\title{
Research on Audit Supervision of Prevention and Control of COVID-19 Under Big Data
}

\author{
Siyi Wang ${ }^{1}$ Guiliang Liu ${ }^{1, *}$ Evgeniy Ivanov ${ }^{2}$
}

\author{
${ }^{1}$ School of Business, Hunan University, Changsha, Hunan 410082, China \\ ${ }^{2}$ Moscow State University, Moscow, Russia \\ *Corresponding author. Email: 17865919805@163.com
}

\begin{abstract}
After the outbreak of Corona Virus Disease 2019 (COVID-19), the efficiency of government work on controlling the epidemic has become the focus of public attention. Based on the current situation, this article analyzes the reasons and feasibility of "off-site first, then on-site" audit supervision of financial funds and donations for the prevention and control of COVID-19 and the necessity of strengthening the tenure responsibility audit of COVID-19 prevention and control cadres by using the big data technology. And recommendations are given on the feasibility of specific paths for the audit supervision of epidemic prevention and control under big data. Specific practical methods of strengthening the tenure responsibility audit of the COVID-19 prevention and control cadres are put forward, providing references for the scientific emergency treatment of follow-up public health emergencies.
\end{abstract}

Keywords: big data audit, tenure responsibility audit, fiscal fund and donation audit, government

administrative efficiency, cadre ability matching, public health, emergency

\section{INTRODUCTION}

With the outbreak of Corona Virus Disease 2019 (COVID-19), some problems in the government's emergency management system have been exposed.

For example, a large amount of protection and other materials donation from places in China and foreign countries are unused. There are many prevention and control cadres who don't take effective and inappropriate prevention and control actions, causing the public's dissatisfaction and substantially reducing the government's administrative efficiency for prevention and control of COVID-19. If the public governance issues arising from the prevention and control of the epidemic are handled properly, it would not only provide an opportunity for social development to change and innovate, but also provide an opportunity for the improvement of government work. At the same time, the big data era has added a lot of new vitality to government work, and it also brings new opportunities for emergency management in terms of thinking, technology, and management methods. The national audit department should conform to the trend of the times, recognize the focus of work, and update working methods. The audit agency should assume vital responsibilities in handling this emergency as follows. On the one hand, it assumes the auditing responsibilities entrusted to audit institutions by laws and regulations, and on the other hand, it meets the needs of the public for the right to know. When the government carries out prevention and control work, the audit agency should expose and investigate major violations of laws and regulations, follow up in a timely manner, pay close attention to the safety of financial funds and materials for the COVID-19 prevention and control, the weak links and potential risks in the government's response work, and economic problems. Proposing countermeasures and suggestions in time can prevent emerging problems from changing trend problems and local problems into overall problems. While improving the image and credibility of the government, it also improves the efficiency of government actions and strengthens the resolve of Chinese people against the COVID-19, helping the epidemic prevention and control work to be carried out efficiently and smoothly with the effectiveness of audit supervision. Therefore, research on the efficiency of government action and audit supervision for COVID-19 control is imminent.

In view of this, the purpose of this article is to build a model for the audit supervision of financial funds and donation for the prevention and control under the support of Chinese big data technology, and explore the specific aspects of the audit supervision of financial funds and donation for the prevention and control around technology and departmental innovation. At the same time, this article designs the path configuration and behavioral requirements of the responsibility audit of preventing and controlling cadres' tenure from the 
perspective of structural and executive motivation based on the improvement of cadre's ability matching degree to promote the improvement of government action efficiency.

The possible contribution of this article is that the existing research is limited to the analysis of the current situation and the requirements of "improving government administrative efficiency", and "advocating the use of off-site auditing" should be proposed in accordance with the times, but there is no specific feasibility of how to achieve the above requirements. Based on the current situation, big data technical support, audit methods and other analysis, this paper gives a feasible detailed realistic path.

\section{ANALYSIS ON THE AUDIT SUPERVISION OF COVID-19 PREVENTION AND CONTROL UNDER BIG DATA}

After the outbreak of the epidemic, the Chinese government made rapid deployment in "promoting the standardized and efficient use of funds and materials for COVID-19 prevention and control", "promoting the implementation of policies as soon as possible, and promoting the full guarantee of the supply of medical protection materials and residents' daily necessities". However, with the improvement of Chinese comprehensive national strength and the quality of life of citizens, the Chinese government and social donors have invested more and more aid funds and materials in response to emergencies, and they have shown a diversified trend. How to carry out the big data under the background of epidemic prevention and control audit supervision to effectively prevent economic crimes, ensure the safety of the national economy, ensure people's livelihood, and improve the administrative efficiency of the Chinese government has become major issues facing national audits. In response to such problems, the author puts forward two suggestions:

- Before conducting on-site audits, auditors can use big data technology to audit and supervise the prevention and control of financial funds and donations.

- Relevant departments should strengthen the audit of the tenure of new crown pneumonia prevention and control cadres.

\section{A. Reasons for using big data technology to audit and supervise the prevention and control of financial funds and donations before conducting on-site audits}

The national audit of public health emergencies is different from the normal national audit. The key task is the audit of financial funds and donations. It requires the audit gate to move forward, intervene in advance, and follow the whole process. On the one hand, most of the related projects aim at investigating the distribution, management, and use of materials for prevention and control after emergencies. In order to adjust in a timely manner and ensure the implementation of various policies and measures, the audit timeliness requirements are high and increased. The difficulty of grasping the key points and pace of the audit has increased, which brings greater challenges to the auditors and audit site management. On the other hand, emergency audit projects often focus on social hotspots and people's livelihood issues. The Chinese government and all sectors of society have high expectations for auditing; at the same time, its audit content requirements are not less than that of ordinary projects. Even due to special circumstances, the audit content is very likely to increase; due to the sudden incident, it may also involve time compression and shortage of project personnel. And these factors undoubtedly increase the audit work pressure. In order to achieve the audit purpose in a short time, the audit institution has to temporarily organize more personnel to conduct surprise operations, but the audit force of the corresponding department is limited, which often causes the audit implementation unit to only draw power from other audit business departments and nonaudit business departments. Even staff from outside units are seconded for reinforcements, resulting in the characteristics of high mobility of audit implementation units and large differences in business familiarity, and increasing audit risks to a certain extent. In response to the epidemic prevention and control audit work, the premature on-site audit by auditors is likely to affect the financial funds for the prevention and control and the time for donations, etc., and it is extremely likely to disrupt the epidemic prevention and control plan, and there is also the possibility of staff infection.

\section{B. Feasibility of using big data technology to audit and supervise the prevention and control of financial funds and donations before conducting on-site audits}

Currently, local audit institutions have already actively implemented General Secretary Xi Jinping's requirement of adhering to audits in accordance with the law, achieved full audit coverage, insisted on strong scientific and technological audits, and made great efforts in human resources, data resources and method resources to build an ecology circle of big data analysis, using audit information technology to fully promote auditing coverage. At the same time, Chinese government departments have issued civilized instructions to audit institutions at all levels to cooperate with finance, development and reform, industry and information technology, financial management departments and financial institutions, 
share information, form a joint force, and require the above-mentioned relevant departments and units to provide relevant data and materials during the audit process, please also provide timely support. The establishment of a multi-industry unified platform network audit application system. Therefore, under the condition that the pre-audit investigation for the collection and use of prevention and control materials is carried out properly, big data audit talents and volunteers of Internet technical talents should be unified deployed to make the best use of the big data audit platform, and the big data audit technology should be used first with the media of the flow of funds and goods.

\section{The inevitability of strengthening the tenure responsibility audit of COVID-19 prevention and control cadres}

As an authority entrusted to manage social resources, the Chinese government has the most extensive and comprehensive resources. Correspondingly, the responsibilities and functions that the Chinese government should assume when managing national political, economic, and social public affairs are enormous. In the face of the unprecedented political, economic and civic life shocks brought about by the epidemic, in just two months there was good news that the situation is changing for the better, indicating that the Chinese government is in the initial stage of the epidemic. And the situation was reviewed and the situation was in focus, and timely and correct decisionmaking and deployment were completed. However, the "frequent problems of cadre malfeasance violations" also revealed that there are shortcomings among the current Chinese government's action mechanism, cadre incentive mechanism, and ability assessment mechanism. And compared to punishing officials after the fact, rationally designing operating procedures and actively constructing a monitoring mechanism to prevent officials' omissions is more meaningful for improving such phenomena. But under normal circumstances, audit supervision cannot interfere with the assessment of Chinese government officials. To a certain extent, this has led to the failure of the public to effectively protect the status of the owner of social resources; on the other hand, the Chinese government's performance of entrusted responsibilities has not been effectively supervised and substantially improved. In other words, the credibility of Chinese government agencies has become questionable. The tenure responsibility audit evaluation method embodies the concept of effective combination of pre-control and post-audit. It evaluates the performance of responsibilities of leading cadres during their tenure from the perspective of responsibility and economics, and discovers and specifies problems existing in leading cadres and their units and departments during their tenure, intending to stimulate the enthusiasm of leaders and responsible persons, prevent problems before they happen, make effective use of audit results, revise work methods in time, and adjust cadres' ability matching.

At present, related issues such as the ability matching of prevention and control cadres directly affect the administrative efficiency of the Chinese government and the credibility of the Chinese government, and further determine the prevention and control effect of the epidemic, the speed of its disappearance, and the mentality of the people across the country to fight the epidemic. Therefore, it is imperative to conduct "off-site first, then on-site" audit and supervision of prevention and control financial funds and donations, and strengthen the responsibility audit of the new crown pneumonia prevention and control officials.

\section{THE SPECIFIC PATH OF EPIDEMIC PREVENTION AND CONTROL AUDIT SUPERVISION UNDER BIG DATA}

\section{A. The specific practical operation method of "off-site first, then on-site" audit supervision of prevention and control financial funds and donations by using big data technology}

First, the staff can use the shared information of various departments and Python + web crawlers to collect detailed data of prevention and control materials Second, it can use the Neo4j graph database to build a relationship network, and then use the Kmeans clustering method to analyze the distribution of screening funds and donations, etc. The "Vertical to End, Horizontal to Edge" audit data model uses the indicator system as the horizontal coordinate, and the financial fund payment data and the data collected at the time of donation as the vertical coordinate to implement departmental budget full coverage audit. After that, people can use intelligent integrated big data analysis system of "model library + geographic information + image and video" trace to the end of the use of funds and donations, implements full-range monitoring of financial funds and donations, and focusing on the collection and use of financial special funds and donations revenue and expenditure management. In this way, a budget execution linkage audit model based on big data correlation analysis is created, and the method of "overall analysis, discovery of doubts, decentralized verification, and system research" is implemented to combine structured data with unstructured and semi-structured data, analyzing the standardization and scientificity of budget preparation and execution, and the effectiveness of the use of funds and donations. Finally, when there is an abnormality at the end of the use of financial funds and 
donations, the auditors will be organized to focus on targeted on-site inspections and conduct key audits of related prevention and control financial funds and donations. The key audit content is shown in "Table I". When conducting on-site audits, people need to pay attention. The audit form must be generated based on the information provided by the audited entity, and the enterprise must not fill in it on behalf of the company, so as to reduce the burden on the audited entity as much as possible and minimize the on-site audit time, especially for emergency areas and the unit's on-site audit time. At the same time, it is necessary to create conditions for the audited unit to focus on the production and circulation of key epidemic prevention and control materials, and not to affect their related work due to follow-up audits. The most important thing is to make the implementation strictly. The audited unit requires epidemic prevention and control, establishes a prevention and control mechanism, implements prevention and control responsibilities, refines and actualizes epidemic prevention and control measures, comprehensively investigates hidden risks, and earnestly completes relevant protection and prevention work to prevent staff from being infected.

TABLE I. THE KEY AUDIT CONTENT FOR PREVENTION AND CONTROL OF FINANCIAL FUNDS AND DONATIONS

\begin{tabular}{|c|c|}
\hline Audit stage & The main content of the audit \\
\hline \multirow{5}{*}{$\begin{array}{l}\text { Procedures for raising financial funds and } \\
\text { donations for epidemic prevention and } \\
\text { control }\end{array}$} & Is the raising agency legal or not \\
\hline & $\begin{array}{l}\text { Whether the borrowing principle, classification governance principle and cost sharing } \\
\text { principle are fully considered when raising }\end{array}$ \\
\hline & Whether to set up a special financial account \\
\hline & Whether there is any hidden money \\
\hline & Whether the received donation is credited to the account in time and in full \\
\hline \multirow{4}{*}{$\begin{array}{l}\text { Procedures for distribution of financial } \\
\text { funds and donations for epidemic } \\
\text { prevention and control }\end{array}$} & Is the allocation timely or not \\
\hline & Is the distribution fair or not \\
\hline & Whether the money and materials are actually needed and can they be used to the full \\
\hline & Whether the distribution meets the reported data \\
\hline \multirow{5}{*}{$\begin{array}{l}\text { Disbursement procedures of financial } \\
\text { funds and donations for epidemic } \\
\text { prevention and control }\end{array}$} & Whether the payment is timely, standardized and reasonable \\
\hline & Whether there are problems such as detention, detention, seizure, embezzlement, etc. \\
\hline & Whether the funds are earmarked \\
\hline & Is the issuance procedure, amount, and target standard and reasonable or not \\
\hline & Whether the payment procedures are complete \\
\hline \multirow{3}{*}{$\begin{array}{l}\text { Procedures for using financial funds and } \\
\text { donations for epidemic prevention and } \\
\text { control }\end{array}$} & $\begin{array}{l}\text { Whether there are unreasonable distribution, corruption, transfer and sale, withholding, } \\
\text { deduction, loss and waste in the use link }\end{array}$ \\
\hline & Whether the usage record is complete and detailed \\
\hline & $\begin{array}{l}\text { Whether to record and summarize and adjust the purchase amount according to the } \\
\text { prevention and control demand at all times }\end{array}$ \\
\hline \multirow{2}{*}{$\begin{array}{l}\text { Management procedures for financial } \\
\text { funds and donations for epidemic } \\
\text { prevention and control }\end{array}$} & Whether to carry out effective recycling and disposal \\
\hline & approval procedure for issuance strictly implemented? a \\
\hline
\end{tabular}

\section{B. Strengthening the specific practical operation methods of the tenure responsibility audit of the COVID-19 prevention and control cadres}

First, in accordance with relevant notices, strict norms and restraint law enforcement regulations, and their own emergency response capabilities, it is required to implement a lifelong accountability system for prevention and control cadres: all provinces and above, cities, counties (districts), townships, Chinese government and related defense should make the implementation of the epidemic prevention and control policy, the implementation of the responsibility system for epidemic prevention and control targets, and the emergency response effect of related emergencies by the main leaders of the control unit and even the village committee are included in the scope of the responsibility audit of the official term. Through the establishment of reverse inspection mechanism, surprise spot inspection mechanism, big data tracking prevention and control cadres economic changes, public supervision and other mechanisms, during the period of epidemic prevention and control, the failure to implement prevention and control policies and requirements during the term of office has caused the deterioration of the epidemic in the area responsible, regardless of reality. If the situation is blindly decisionmaking, causing serious consequences, using power to intervene, committing corruption, delayed reporting, concealing any irregular behavior, and obstructing supervision and law enforcement, the relevant leaders and responsible persons shall be held accountable in accordance with laws and disciplines. At the same time, the Chinese government and auditing agencies at all levels will also organize the supervision of the implementation of the epidemic prevention and control work in conjunction with the epidemic prevention and control work plans and plans of relevant departments at all levels, and regularly report them. Afterwards, supervisory agencies at all levels discover violations of regulations or violations of the law or fail to promptly investigate and deal with violations after receiving 
reports of violations or violations, fail to perform their duties in supervision and law enforcement, and impose penalties on violations of laws and regulations that are unreasonable, and will not transfer or accept suspected criminal cases or shirk law enforcement and other regulatory omissions. The relevant units and personnel shall be held accountable in accordance with law and discipline. If state functionaries shelter or condone violations of laws and regulations, or fail to investigate and deal with them well, and are suspected of duty crimes, relevant personnel must be promptly transferred to the People's Procuratorate. Finally, at the end of the tenure responsibility audit, the audit unit shall integrate the above investigation content, issue an audit report, and submit a report on the results of the economic responsibility audit of leading cadres during the tenure of the Chinese government at the corresponding level and the higher level, and prepare the discipline inspection and supervision organs, personnel departments and related departments at the same level. According to the audit report, the Chinese government at all levels adjusts the ranks of cadres and the capable ones, and adjusts the methods and methods of prevention and control in real time, in order to improve the harmonious matching of cadres and abilities, so as to minimize cadres' malfeasance and violations and improve the administrative capacity of the Chinese government, to enhance the credibility of the Chinese government, and win this epidemic prevention and control sniper battle with the highest combat effectiveness and Chinese speed.

\section{CONCLUSION}

A scientific and effective public health emergency audit emergency route is one of the important components of the Chinese government's emergency management, and it is also an important guarantee for the Chinese government to successfully respond to public health emergencies. This article focuses on the main content that the audit department needs to control during the emergency management of public health incidents in two aspects: first is the follow-up audit of donated materials to ensure and improve the implementation of important reforms such as people's livelihood; second is to strengthen the operation of power and deepen the policy implementation of responsibility audit supervision of cadres' tenure. In response to the audit focus of public health incidents, the current epidemic situation and the emergence of public governance issues, two practical suggestions are put forward for the audit and supervision of epidemic prevention and control in the context of big data: First, auditors can use big data technology to conduct "offsite first, then on-site" audit supervision of prevention and control of financial funds and donations. Second, relevant departments should strengthen the duty audit of cadres for the prevention and control of new crown pneumonia. This article combines the unique attributes and functions of the big data era with the audit and emergency management of public health emergencies, discusses the intelligent follow-up audit model based on big data, and proposes the use of big data technology to prevent and control financial funds and donations. The specific path of on-site and off-site audit supervision will continue to deepen the follow-up audit of epidemic prevention and control, improve the timeliness of audits, and give full play to a constructive role. At the same time, it emphasizes on strengthening the responsibility audit of the term of office of prevention and control cadres, and proposes specific implementation paths, so as to promote the implementation of various prevention and control measures, and coordinated and advanced various tasks. From the perspective of audit practice, it has enriched and expanded emergency management measures for public health incidents, providing references for the scientific emergency response of subsequent public health emergencies.

\section{References}

[1] Alali A F,Pan F. Use of audit software: Review and survey[J] Internal Auditing,2011, 26(5):29-36.

[2] Chen Wei, Smieliauskas Wally. Opportunities, challenges and methods of electric data auditing in big data environments[J]. Computer Science,2016,43(1):8-13,34.(In Chinese )

[3] Robert L B, Harold E D. Computer-assisted audit tools and techniques: Analysis and perspectives[J]. Managerial Auditing Journal,2003, 18 (9):725-731.

[4] Shleifer, A., "State versus Private Ownership", Journal of Economic Perspectives, 1998, 12(4), pp.133-150.

[5] Liu, H., and X. Li, "Government Decentralization and Corporate Fraud: Evidence from Listed State-owned Enterprises in China", China Journal of Accounting Studies, 2015, 3(4), pp.320-347.

[6] Staff,S. Dealing with data. Challenges and opportunities.Introduction[J].Science,2011,331(6018):692.

[7] Taylor, M. H., “A Proposed Framework Emphasizing Auditor Reliability Over Auditor Independence”, Accounting Horizons, 2003, 17(3), pp.257-266.

[8] Wang Yuanzhuo, Jin Xiaolong, Cheng Xueqi. Network big data: Present and futrue[J].Chinese Journal of Computer,2013,36(6):1125-1138.(in Chinese)

[9] Choi, J. H., “Geographic Proximity between Auditor and Client: How Does it Impact Audit Quality?" , Auditing: A Journal of Practice \& Theory, 2012, 31(2), pp.43-72 ;

[10] Jensen, K., J. M. Kim, and H. Yi, "The Geography of US Auditors: Information Quality and Monitoring Costs by Local versus Non-local Auditors", Review of Quantitative Finance and Accounting, 2015, 44(3), pp.513-549.

[11] Li Xuelong, Gong Haigang. A survey on big data systems[J].Scientia Sinica Informationis,2015,45(1):1-44.

[12] Richardson, S., "Over-investment of Free Cash Flow", Review of Accounting Studies, 2006, 11(2-3), pp.159-189.

[13] Earley C E.Data analytics in auditing: Opportunities and challenges[J].Business Horizons, 2015,58(5):493-500.

[14] Dechow, P. M., R. G. Sloan, and A. P. Sweeney, "Detecting Earnings Management", The Accounting Review, 1995, 70(2), pp.193-225. 
[15] Lambrechts A J, Lourens J E,Millar P B,et al. Global Technology Audit Guide: Data Analysis Technologies[M].FL: The Institute of Internal Auditors,2011.15-27.

[16] Kang, H. C., R. M. Anderson, K. S. Eom, et al., "Controlling Shareholders' Value, Long-Run Firm Value and Short-term Performance", Journal of Corporate Finance, 2017, 43(2), pp.340-353.

[17] Alexander K,Ephraim F S, Miklos AV. Continuous online auditing: a program of research [J].Journal of Information Systems, 1999,13(2):87-103.

[18] Carey P,Liu L,Qu W.Voluntary corporate social responsibility reporting and financial statement auditing in China[J].Journal of Contemporary Accounting and Economics,2017,13(3):244-262.

[19] Yoon K,L Hoogduin,Li Z.Big data as complementary audit evidence[J].Accounting Horizons, 2015,29(2):431-438.

[20] Leung S,Parker L,Courtis J.Impression management through minimal narrative disclosure in annual reports[J].British Accounting Review,2015,47(3):275-289.

[21] Zhang J,Yang X, Appelbaum D. Toward effective big data analysis in continuous auditing[J].Accounting Horizons, 2015,29(2):469-476.

[22] Nazari J,Hrazdil K,Mahmoudian F.Assessing social and environmental performance through narrative complexity in CSR reports[J].Journal of Contemporary Accounting and Economics,2017,13(2):166-178.

[23] D A Appelbaum, M A Vasarhelyi. Big data and analytics in the modern audit engagement: Research needs[J].Auditing A Journal of Practice \& Theory,2017,36(4):1-27.

[24] Kurihama R.Role for auditing in corporate social responsibility and corporate governance:Under new corporate view[J].Corporate Ownership \& Control,2007,5(1):109-119.

[25] Colombo T,Fröning H,Garcìa $P$ J,et al.Optimizing the datacollection time of a large-scale data-acquisition system through a simulation framework [J]. The Journal of Supercomputing,2016,72(12):4546-4572. 